\title{
Role of Knowledge Acquisition on Firm Performance in the Context of Small and Medium Enterprises in Meru County, Kenya
}

\author{
Cosmus Muriithi Gatuyu, Godfrey Muigai Kinyua
}

School of Business, Kenyatta University, Nairobi, Kenya

Email address:

cosgat@gmail.com (C. M. Gatuyu), cgatuyu@rti.org (C. M. Gatuyu), jefkinyua@gmail.com (G. M. Kinyua)

\section{To cite this article:}

Cosmus Muriithi Gatuyu, Godfrey Muigai Kinyua. Role of Knowledge Acquisition on Firm Performance in the Context of Small and Medium Enterprises in Meru County, Kenya. Journal of World Economic Research. Vol. 9, No. 1, 2020, pp. 27-32.

doi: 10.11648/j.jwer.20200901.14

Received: November 14, 2020; Accepted: December 30, 2020; Published: January 7, 2020

\begin{abstract}
Small and Medium Enterprises (SMEs) are touted as the silver bullet in the revival and flourish of any country's economy. It has the capacity to gainfully engage the highest number of work force. Effective and efficient performance of the sector is critical to economic growth. Large amounts of resources allocated to the sector have borne little fruit with failure reports in the last decade. This paper seeks to establish the influence of knowledge acquisition strategies on the performance of Small and Medium Enterprises (SMEs) within Meru county. The study was based on three theories; The Resource Based View theory of the enterprise (RBV), Organisation Learning (OL) and Knowledge Based View (KBV) theories. The research study employed a descriptive survey research design. The study's target population was 500 SMEs in Meru County from which a sample of 150 SMEs was selected using stratified random sampling. The SMEs in Meru County constituted the unit of analysis while the managers, proprietors and senior staff constituted the unit of observation. The researcher utilised questionnaires to collect primary data. The data collection instruments were tested for construct, content and face validity. Cronbach Alpha Coefficient was used to test for reliability. Descriptive and inferential data was analysed. Summary measures of the sample which included frequency distribution tables, percentages, standard deviations and mean was generated from the descriptive statistics. Multivariate analysis and inferences made at $95 \%$ confidence level included the inferential statistics. Owners of SMEs will find the study's results effective in enhancing their entity performance as they can make viable business decisions based on acquired knowledge. Academicians, researchers and lay readers with an interest in knowledge acquisition will find the study useful. From the findings, SMEs in Meru County embraced knowledge acquisition strategies and practises to a moderate extent. The study concludes that the knowledge acquisition strategies had a significant positive effect on the performance of SMEs in Meru County. From the study findings, it can be concluded that there is a strong relationship between the study variables as shown by a correlation coefficient of 0.781 . The study concludes that the SMEs have enhanced knowledge acquisition through use of capacity development, mentorship programs, modern technology and consultations. It is a recommendation of the study that the SMEs should embrace the trainings and microfinance services offered by MicroFinance Institutions and other financial sector players to enhance their capacity in knowledge acquisition.
\end{abstract}

Keywords: Small and Medium Enterprises, Knowledge Acquisition, Performance of SMEs

\section{Introduction}

SMEs are documented as some of the important businesses taking part to enhance employment and commercial growth for many nations [22]. For most developing nations SMEs have been documented as key enterprises supporting the employment sector and largely contributing to their economic growth and development. SMEs have been approximated to be responsible for more than $60 \%$ of the Gross Domestic Product (GDP) for low and middle income countries and employing more than $70 \%$ of the population [19] SMEs are credited as one of the biggest players in both national and regional development for most countries, both the less developed, developing and developed [13]. It is notable that 
the SME sector is an important sector to further innovativeness, competitiveness and entrepreneurship and the states and governments should be proactive in their support for the sector to establish efficient, innovative systems for development and problem solving [1].

Knowledge on the other hand can be viewed as the crucial strategic resources for ensuring a firm's survival and success in the long-term. It's exclusive to a firm and difficult to imitate or ape [16]. Knowledge management is a central consideration for technology and innovation coordination [15]. Researchers in many sectors have been spurred by this fact to centre their researches on the inner components of business as crucial to their market attractiveness specifically those of immaterial nature that are associated to a firm's knowledge gained over time [23]. Knowledge Acquisition processes of an organization are centred on the greatest strategic framework meant to create and preserve organizational facts to attain modest objectives [18].

Kenya as a country has over 1.6 Million recognized SMEs forming part of the largest sector in the business enterprises, amounting to almost $96 \%$ of all businesses in the country. It contributes almost $18.4 \%$ of Kenya's GDP with an employability rate of $83 \%$ of Kenya's workforce [14]. This reflects the efficiency of SME sectors in the country; hence the embracement of Knowledge Management practices to the sector is key to effective and efficient service provision as well as business growth.

Organizational performance reflects on the firm's capacity to effectively acquire and use its scarce resource to attain its operational objectives [12]. A business' performance can be valued as a major criterion that can be used to measure its success. Prior researchers have conceptualized a firm's performance with market share, new products launched and measures of return on assets [13]. Sales growth, overall client satisfaction and profitability have also been identified as other indicators of a firm's performance [4]. In the SME sector, financial issues and other operational measures would be always be used as key measure of organizational performance [24]. However, value return on assets, dividend, return on investment and return on shareholder's equity have been identified as key measures of organizational performance [21]. On the other hand, three main strategies of measuring a firm's performance have been identified [17]. These include organizational efficiency focused on its product quality, success in providing new goods and amenities, growth in market as indicated by the volume of sales and the businesses' profitability. A firm's performance would also be measured based on its profitability, life quality, innovativeness, efficiency, effectiveness, and productivity [7] Since there exists varying indices of measuring organizational performance, some of the most used strategies have been chosen for the study. These strategies include productivity, innovativeness, client satisfaction, work relationships, return on assets and staff output.

Meru as a county has approximately 10,000 registered SMEs with new ones being registered each day. The SME sector within the county has been highly recognized by many entrepreneurs based on its low capital requirements to start. However, the sector has been characterized by a high mobility rate, a factor that highly restricts their ability to thrive [2]. This can be attested by SME's in part being very erratic and encountering an astounding rate of business shrinkage and conclusion [25]. Meru County government has invested considerable effort to aid the progress of the SMEs sector. This paper will seek to establish the role that knowledge acquisition plays in the performance of the SMEs in Meru County.

\section{Theoretical Literature Review}

According to this model, organizations operate effectively and create value on their products once they execute approaches by utilizing their capabilities and internal resources. For knowledge management procedures that deal with the acquisition of knowledge to coordinate and enhance the internal resources of a firm and improve its performance. The Resource Based View of an organization values knowledge as one of the key strategic and crucial resources of an organization [11]. It also recognizes the fundamental responsibility for the organization within the development and use of knowledge. [12] Arguments have been advanced that the Resource Based View of an enterprise envisions a firm as a disseminated system of knowledge consisting of knowledge that holds staff and believes an organization's responsibility includes coordinating the staff so that they can develop abilities that account for an organization. This approach indicates that knowledge equips firms with varying capabilities and abilities that determine the firm's ability to perform and compete in the marketplace. [16] Another school of thought advance the argument that competitive organisations are those that have structures for efficiently developing, locating, acquiring and distributing knowledge and expertise with the objective of applying knowledge in solving issues and utilizing other organizational opportunities. Various researchers accomplished on a similar topic just the theory as a process oriented.

Absorptive capacity of a firm is considered to be reliant on previous associated knowledge of the firm. Absorptive capacity of a firm can be improved via Knowledge Management procedures and techniques that allow it to obtain, adapt as well as utilise available and innovative knowledge by infusing with internal resources while it still sustains competitiveness within the market.

\section{Empirical Literature Review}

A study was conducted about the effects of knowledge management practices on a firm's operational growth [9]. The objectives of the study involved investigating the effects knowledge management has on SMEs using causal modelling. Simple random sampling technique was used to select the 282 executive managers from the selected enterprises which the study utilized and then the data being executed using the causal equation mode. The analysis' 
findings would express out that knowledge creation, sharing attainment, implementation, and storage offer a crucial loading factor on knowledge management and also efficiency, employee outputs, innovation and client fulfilment.

Another study that explored the effects of knowledge management practices on a firm's operational growth within the Hospitality Trade in Zimbabwe was carried out [20]. The study would express that knowledge management practices affected the sector's performance. [20] The research that utilized processes, intellectual capital and Public Investment Corporations (PICs) approach addressing 3 hotels within the industry utilizing 50 respondents comprising of 15 managers and 35 non managerial staff. The research findings would unveil that a firm with knowledge management practices enhances the innovative ideas of the firm, new products and also provide different ways of accomplishing various organizational activities that generally enhances the firm's efficiency after having effectively adopted stratified random sampling.

A different research was conducted focusing on knowledge management practices among SMEs and other large firms in Malaysia [8]. Knowledge management strategies were found to have a great impact on both large and small firms in the region [8]. This is majorly because the study insinuated that knowledge management practices are part and parcel of a business' operating procedures. The procedures need turning individual knowledge into firm knowledge, which can be broadly distributed within a business and effectively utilised. The competitiveness of a firm as well relies heavily on the quality of knowledge they utilize too and other business processes greatly. On the other hand, the outcomes would portray that the effects of Knowledge Management practises on fiscal and non-fiscal differs between small (SMEs) and large organizations. The study's findings would enhance the firm's financial and non-financial performance by effectively applying knowledge management practices.

\section{Methodology}

The researcher has employed descriptive survey research design for this study. This research design is appropriate for the study as it aids in defining and describing phenomena by advancing an academic argument through the development of a research query or procedures by data gathering and tabulation of the data based on its interaction or frequencies.

The study was focused on a population of 500 SMEs within Meru County. The participants included the SME owners and managers. The target managers were chosen as they have a definite understanding of the SME's nature of operation. The implications are that the study's outcomes can be effectively generalized without significant mistakes. The entire population consisted of health, financial, logistics, retail, automotive, hospitality, real estates, and energy within the area of study.

Stratified random sampling was used to select a sample for the process. The population was stratified into industry sections from which a sample was randomly selected for representation. A sample of 150 SMEs was selected representing $30 \%$ of the total population.

The research collected primary data through the use of questionnaires. The questionnaires were administered to the respondents via drop and pick techniques to the selected participants. The investigator also made use of technology and programmed an online form using Survey Monkey ${ }^{1}$ and google forms ${ }^{2}$ to have the participants fill them out. The investigator ensured informed consent on the respondents by informing them that the research tools being administered were for academic research only and all the responses will be treated anonymously. There was not any requirement to selfidentify in the tools. The investigator guaranteed the respondents that any provided information will be confidential as it was only meant for academic research only. The researcher got a consent letter from the University and a research licence from National Centre for Science, Technology and Innovation (NACOSTI) to show authenticity of the research and create confidence among the respondents during data collection. To ease data collection and enhance convenience for the respondents, the researcher utilised digital platforms such as WhatsApp, Facebook and Twitter to increase the response rate.

After data collection, it was cleaned and prepared for analysis. Coding, editing and categorizing and the process was supported by use of Statistical Package for Social Sciences (SPSS) version 20.0 and excel in some instances. Descriptive and inferential statistics was produced. Descriptive statistics consists of the frequencies and percentages as inferential statistics consists of multiple linear regressions approach. The descriptive statistics such as standards deviation and means were used in analysing the collected data. Simple regression analysis and Pearson correlations was computed to test the strength and nature of the relations between variables.

This study made use of simple linear regression approach to examine the association between the dependent and independent variable that are illustrated in the approach below.

$$
\mathrm{B}=\beta_{0}+\beta_{1} \mathrm{~A}_{1}
$$

Where:

$$
\mathrm{B}=\text { Performance of SMEs } \mathrm{A}_{1}=\text { Knowledge acquisition }
$$

Based on the approach above $\beta$ is valued to be a constant value as the coefficient $\beta_{1}$ was employed to evaluate the responsiveness of the dependent variable $(B)$ to each unit change in the independent variable $\left(\mathrm{A}_{1}\right)$. $\varepsilon$ represents the error value that takes into consideration the un-illustrated variations in the approach. The outcome was then presented through frequency distribution tables.

\footnotetext{
1 Survey Monkey is a free online platform used to conduct surveys and gather information easily. It is a flexible for use in a variety of ways. Its available on www.surveymonkey.com

2 Google forms are an open source platform to conduct surveys developed by Google. Available on https://www.google.com/forms/about/
} 


\section{Research Findings and Discussions}

\subsection{Descriptive Findings}

\subsubsection{Knowledge Acquisition and Performance of SMEs}

The study sought to establish how the acquisition of knowledge influenced the performance of SMEs across different sectors of the economy within the county of Meru. The researcher asked the respondents to rate how much they agreed with some statements on knowledge acquisition. A Likert scale of 1-5 was done with 1 being "strongly disagree" and 5 being "strongly agree". Table 1 below represents the findings:

Table 1. Knowledge acquisition and performance of SMEs.

\begin{tabular}{lll}
\hline Statements & Mean & Std. Dev \\
\hline External surveys are conducted for knowledge acquisition by the SMEs & 2.51 \\
Employees are taken for external training by the SMEs to acquire new knowledge. & 2.61 \\
Hiring skilled labour is a big emphasis by the SME & 3.04 \\
Technological advancement is emphasised on by the SME & 3.41 \\
\hline
\end{tabular}

Source: Field data, 2019

From the above findings, the respondents for the study mainly posted a neutral response or moderately agreed that their business entities carry out external surveys as an effort in knowledge acquisition. Employees are also taken for external training to acquire new knowledge; emphasis is put on hiring skilled labour and the SMEs put significant emphasis on technological advancement. This is as indicated by means of 2.51, 2.61, 3.04 and 3.41 respectively.

From this data, it is evident that the firms employed knowledge acquisition strategies through surveys, training, hiring skilled labour force and integration of technology in their operations.

The respondents further indicated that the SMEs can acquire more knowledge on business management and performance by interacting with other players in the sector, attending and getting trainings and capacity development from financial institutions and organizations. By acquiring new skills and knowledge, the enterprises are able to improve competitiveness and performance as also indicated by In a study on the taxonomy of knowledge management practices among manufacturing firms, it was established that firms need to use target costing systems to create, transfer, acquire and share knowledge [5]. Knowledge acquisition enhances firm capacity to perform efficiently and effectively.

\subsubsection{Performance of SMEs}

This research also sought to establish the performance of the SMEs for the last year. A five point Likert scale was used and participants were asked their level of agreement with the following statements where 1 was "Strongly Disagree" and 5 was "strongly agree". The statements were based on various indicators of performance. The results are presented in Table 2 below:

Table 2. Performance of SMEs.

\begin{tabular}{lll}
\hline Statements & Mean & Std. Dev \\
\hline Productivity has improved in the SME over the last year & 3.55 \\
More customers, than the previous years have come to the SME & 3.38 \\
Profitability is higher this year in the SME than in the last years & 3.57 \\
There are more repeat customers this year than in the previous years & 3.45 \\
Customers expressed more satisfaction with the products/services of the SME & 3.25 \\
There is evident improvement in work relationships in the SME & 0.806 \\
\hline
\end{tabular}

Source: Field data, 2019

From the findings presented above, the respondents showed agreement that the SMEs have witnessed an improvement in productivity, customer retention and profitability as shown by computed means of $3.55,3.38$ and 3.57 on the score items respectively.

There were also indications that to a moderate extent the SMEs have increased their customer base, made improvements in customer satisfaction and there was evidence on improvements in work relationships as indicated by a computed mean of 3.38, 3.25 and 3.04 respectively for the test items. From this data, it is an indication that the firms had improved their performance significantly given the integration of knowledge acquisition strategies in their operations.

\subsection{Inferential Statistics}

To be able to find out the level of correlation between knowledge acquisition strategies and the performance of SMEs within the county of Meru, inferential statistics were conducted. ANOVA, Regression Coefficients and Model summary were done, and the findings are as outlined below:

Model Summary: Coefficient of determination and coefficient of adjusted determination findings are as shown in Table 3 below.

Table 3. Model Summary.

\begin{tabular}{lllll}
\hline Model & R & R Square & Adjusted R Square & Std. Error of the Estimate \\
\hline 1 & $0.781^{\mathrm{a}}$ & 0.768 & 0.771 & 1.511342 \\
\hline
\end{tabular}

Source: Field data, 2019 
From the findings, the coefficient of correlation $\mathrm{R}$ was 0.781 which was a strong indication of $\mathrm{s}$ strong positive correlation between the variables for the study. Coefficient of adjusted determination R2 was 0.771 , expressed as a percentage as $77.1 \%$ which is an indication of changes of dependent variable, in this case, SME performance, can be explained by knowledge acquisition. The remaining $22.9 \%$ can be explained by other factors that are not within the scope of the current study.

\section{ANOVA}

Analysis of Variance (ANOVA) was carried out at 95\% significance level. $\mathrm{F}_{\text {Calculated }}$ and $\mathrm{F}$ Critical findings are as shown in Table below.

Table 4. Analysis of Variance (ANOVA).

\begin{tabular}{lllll}
\hline Model & Sum of Squares & df & Mean Square & F \\
\hline Regression & 781.011 & 25 & 31.24044 \\
Residual & 341.132 & 100 & 3.41132 \\
Total & 1192.143 & 125 & & 9.15787 \\
\hline
\end{tabular}

Source: Field data, 2019

From the findings above, it can be argued that F Calculated was 9.15787 and F Critical was 4.3117 , this means that $\mathrm{F}$ Calculated $>$ F Critical which is a sign that the overall regression mode was significant for the study. The $\mathrm{p}$ value was $0.000<0.05$ an indication that knowledge acquisition significantly influenced performance of the SMEs.
Coefficients of Regression

Coefficient of regression was utilised to establish the individual influence of the identified study variables to business entity performance. The findings are presented in Table below.

Table 5. Coefficients of Regression.

\begin{tabular}{lllll}
\hline \multirow{2}{*}{ Model } & \multicolumn{2}{l}{ Unstandardized Coefficients } & \multicolumn{2}{c}{ Standardized Coefficients } \\
\cline { 2 - 3 } & B & Std. Error & Beta & \\
\hline (Constant) & 5.751 & 0.612 & & 2.319 \\
Knowledge acquisition & 0.781 & .101 & .101 & .000 \\
\hline
\end{tabular}

Source: Field data, 2019

From the above, the resulting equation was

$\mathrm{B}=5.751+0.781 \mathrm{~A}_{1}$ Where: $\mathrm{A}_{1}=$ Knowledge acquisition

From the research, it was established that with all the variables held constant, the performance of the business entities will be at 5.751. If there is a unit increase in the variable, knowledge acquisition, while all the other variables are held constant, the SME performance would be at 0.781 .

From the findings, all the independent variables had a $\mathrm{p}$ value of $0.000<0.05$ which is an indication that knowledge acquisition strategies have a significant and positive effect on the performance of business entities under SMEs within the county of Meru. Knowledge acquisition practices were established from the research findings to lead to new products, development of new ideas and innovations to improve organizational performance.

\section{Conclusions and Recommendations}

The study found that the acquisition of knowledge by an SME in Meru County can positively influence its performance. The respondents to a moderate extent were in agreement that their business entities conduct external surveys, facilitate and encourage their employees to attend external trainings, put a lot of emphasis in the hiring of skilled employees and have a big emphasis on technological advancements as knowledge acquisition strategies. The respondents were also in agreement that the SMEs can acquire more knowledge on business management and performance by interacting with other players in the sector, attending and getting trainings and capacity development from financial institutions and organizations. The firms to a moderate extent employed knowledge acquisition through surveys, training, hiring skilled labour force and integration of technology in their operations. A business entity's competitive edge in their industry can be boosted by acquiring knowledge in their field of operation or expertise as well as improving their overall performance.

It can be concluded that SMEs within the county of Meru appreciate and incorporate knowledge acquisition strategies in their enterprises to a moderate extent. It is evident that knowledge acquisition strategies were found to have a significant and positive effect or influence on the overall performance of SMEs within the county of Meru.

The existence of a strong correlation, as shown by a 0.781 correlation coefficient among the study variables is another strong conclusion the study can make. SMEs within Meru County have improved knowledge acquisition strategies through the use of experts, consultations, internship and mentorship programs, modern technology and consultations among many others.

SMEs should embrace the trainings and microfinance services offered by Micro-Finance Institutions and other financial sector players to enhance their capacity.

The SMEs need to work as a team, integrate and coordinate to improve their knowledge base, skills and ideas that lead to improvement of their performance. 


\section{References}

[1] Agupusi, P. (2007, July). Small business development and poverty alleviation in Alexandra, South Africa. In second meeting of the Society for the Study of Economic Inequality, East Anglia, Norwich, UK, ECINEQ Society, Berlin, (P.Agupusi@uea.ac.uk) Altenburg, T, and Drachenfels, CV (2008) Creating an enabling environment for private sector development in Sub-Saharan Africa, Universität zu Köln, Luxembourger Str (Vol. 32550939).

[2] Ahwireng-Obeng, F. 2003. Youth economic empowerment in South Africa: Entrepreneurship versus small business policy. In: Proceedings at the 48 the Conference of the International Council for Small Business (ICSB), Dublin, 9-11 June: 1-18.

[3] Ali E. Akgün, Huseyin Ince, Salih Z. Imamoglu, Halit Keskin \& İpek Kocoglu (2014) The mediator role of learning capability and business innovativeness between total quality management and financial performance, International Journal of Production Research, 52:3, 888-901, DOI: 10.1080/00207543.2013.843796.

[4] Baker, W. E., \& Sinkula, J. M. (1999) The Synergistic Effect of Market Orientation and Learning Orientation on Organizational Performance. Journal of the Academy of Marketing Science, 27 (4), 411-427.

[5] Choe, J. M. (2011). The taxonomy of knowledge management practices in manufacturing firms: Use of target costing and IT infrastructure. African Journal of Business Management, 5(15), 6597.

[6] Choi, B. \& Lee, H. (2003), "An empirical investigation of knowledge management styles and their effect on corporate". Companies Create the Dynamics of Innovation. New York: Oxford University Press.

[7] Daily, B. F. and Huang, S. (2001) Achieving Sustainability through Attention to Human Resource Factors in Environmental Management. International Journal of Operations \& Production Management, 21, 1539-1552. http://dx.doi.org/10.1108/01443570110410892.

[8] Daud, S. (2012). Knowledge management processes in SMES and large firms: A comparative evaluation. African Journal of Business Management, 6 (11), 4223.

[9] Gholami, M. H., Asli, M. N., Nazari-Shirkouhi, S., \& Noruzy, A. (2013). Investigating the influence of knowledge management practices on organizational performance: an empirical study. Acta Polytechnica Hungarica, 10 (2), 205-216.

[10] Gold A. H, Malhotra A, Segars A. H. (2001). Knowledge management: An organizational capabilities perspective. J. Manage. Inform. Syst, 18 (1): 185-214.

[11] Grant, R. M. (1996). Toward a knowledge-based theory of the firm. Strategic management journal, 17 (S2), 109-122.
[12] Griffin, R. C. (2006). Water Resource Economics. The Analysis of Scarcity, Policies, and Projects. Journal of Economics 91(2):203-207 Available: 10.1007/s00712-0060251-1.

[13] Jaworski, B J., and Kohli, A K, (2011), Market Orientation: Antecedents and Consequences. Journal of Marketing 57, pp. 53-70.

[14] Kenya National Bureau of Statistics (2018) Kenya Economic Survey of 2018. Government Printers, Nairobi - Kenya. Accessed from: https://africacheck.org/wpcontent/uploads/2019/03/Economic-Survey-2018.pdf

[15] Kinyua, M. G (2015). Relationship between Knowledge Management and Performance of Commercial Banks in Kenya. Kenyatta University Press. Available on http://irlibrary.ku.ac.ke/handle/123456789/17807

[16] Kogut, B., \& Zander, U. (1992). Knowledge of the firm, combinative capabilities, and the replication of technology. Organization science, 3 (3), 383-397.

[17] Koh, S. C. L., Demirbag, M., Bayraktar, E., Tatoglu, E., \& Zaim, S. (2007). The impact of supply chain management practices on performance of SMEs. Industrial Management \& Data Systems, 107 (1), 103-124.

[18] Liebeskind J. P (1996) Knowledge, Strategy and the theory of the firm. Strategic Management Journal/Volume 17, Issue S2.

[19] Lukacs, E., (2005). The Economic role of SMEs in World Economy especially in Europe. Journal of European Integration Studies, 4, 1.

[20] Mahapa, M. (2013). Impact of knowledge management practices on organizational performance in the hospitality industry of Zimbabwe. Public Administration Research, 2 (1), 76.

[21] McMahon, R., LeCornu, M., Forsaith, D., \& Stanger, A. (1996). The small enterprise financial objective function: An exploratory study. Journal of Small Business Management, 34 (3), 1.

[22] Mead D. and Liedholm C. (1999) Small Enterprises and Economic Development: The Dynamics of micro and Small Enterprises. Routledge Publishers, New York.

[23] Nonaka I. and Takeuchi H. (1995) The Knowledge Creating Company: How Japanese Companies create the dynamics of innovation. Oxford University Press, New York - USA.

[24] Ramanujam V. and Venkatraman N. (1986) Measurement of Business Economic Performance: An Examination of Method Convergence. Journal of Management, Volume: 13 issue: 1, page (s): 109-122.

[25] Van Den Berg, (2004). Interactive information consulting system for South African small businesses: Part 1. South African Journal of Information Management, Volume 6 Number 2. 